\title{
.
}

\section{COVID-19 and international primary care systems: Rebuilding a stronger primary care}

\author{
Luke N Allen ${ }^{1,2 \star}$, Hajira Dambha-Miller ${ }^{3}$
}

${ }^{1}$ Guest Editor and Editorial Board Member, BJGP Open, London, UK; ${ }^{2}$ GP Academic Clinical Fellow, Nuffield Department of Primary Care Health Sciences, University of Oxford, Oxford, UK; ${ }^{3}$ Editor-in-Chief, BJGP Open, London, UK

\section{*For correspondence:} drlukeallen@gmail.com

Competing interest: See page 2

Received: 12 August 2020

Accepted: 13 August 2020

Published: 09 September 2020

(C)This article is Open Access: CC BY license (https://creativecommons.org/licenses/by/4.0/)

Author Keywords: International, Service organisation

Copyright (C) 2020, The Authors; DOI:10.3399/

bjgpopen20X101130
In this BJGP Open collection, we examine how international primary care systems have performed in response to COVID-19. The past few months have seen rapid change and adaption of primary care systems to meet unprecedented new challenges. The pandemic has also exposed critical weaknesses in systems all over the world. ${ }^{1}$

The World Health Organization (WHO) and the World Organization of Family Doctors (WONCA) contend that an ideal primary care system should fulfil the core characteristics laid out by Barbara Starfield: ${ }^{2}$ primary care should be accessible, affordable, available at the time of need, and represent the 'front-door' to the health system. It should provide ongoing care and coordination with other specialists and focus on individuals and their families beyond their biological disease. ${ }^{3,4}$ The Astana Declaration ${ }^{5}$ and the WHO Vision for Primary Health Care in the $21^{\text {st }}$ Century ${ }^{6}$ also make a case for empanelment (working for a listed or geographically defined population) and a model of primary care that is engaged with population health and the wider social determinants of health., ${ }^{7,8}$

Using a questionnaire that aligned with the Starfield principles, Goodyear-Smith and colleagues survey 1035 primary care leaders across 111 countries to assess the extent to which domestic primary care systems meet these standards. ${ }^{9}$ Few countries scored well in every domain, and those perceived as having a prepared pandemic plan and a strong primary care system still faced high rates of COVID-19 mortality. This important benchmarking study highlights the fact that all nations have room to improve.

Our second article in this collection is from Huston and colleagues, who provide a commentary on the primary care response to COVID-19 in six well-resourced countries: Australia, New Zealand, Canada, the Netherlands, the UK and the US. ${ }^{10}$ Their work identifies the specific areas where COVID-19 has directly spurred progress, as well as exposing latent weaknesses and even reversing gains made over previous decades. The pandemic has deepened integration between primary care and public health services, improved access by expediting the adoption of telemedicine, and forced providers to proactively engage with local epidemiological data. However, the authors also observe that the pandemic has disrupted the coordination of non-COVID services and the management of chronic conditions, constrained access for those unable to use phone or video-calling, and forced many feefor-service centres to close or furlough staff in the US and Canada.

We then present an article from a low-income country, Cameroon. Ngo Bibaa shares her primary care experiences on the challenges of managing COVID-19 in rural Africa. ${ }^{11}$ Improvements to access through video-consulting and telemedicine have not been logistically possible. Basic personal protective equipment has been unobtainable. However, information dissemination and training systems have been working well, allowing the rapid adoption of infection control and prevention measures across the country. The author proposes a framework for what the 'new normal' should look like, using pandemic response to advance the development of strong primary care along the Starfield and broader Astana Declaration principles. In Ngo Bibaa's model, all primary care functions are positioned to address wider social determinants of health with better integration into local communities and the broader 
health system. Although this model is proposed specifically for Cameroon, it aligns closely with the 'three pillars' of primary care; empowered people and communities; multisectoral policy and action; and integrated primary care and public health as the core of health services. ${ }^{12}$ This work also resonates with calls for European primary care to engage more deeply with social determinants in Europe, ${ }^{13}$ and the new conceptual framework on the levels of engagement with the social determinants in the upcoming WHO Bulletin special issue on primary health care. ${ }^{14}$

COVID-19 has revealed the areas where progress is needed most. Opportunities to improve coordination with public health and other specialities, as well as expanding access through telemedicine, extended opening hours, and new community clinics should not be misspent. The excess non COVID-19 deaths observed in many countries ${ }^{15}$ should prompt deeper investment in chronic management, improved prevention strategies, and more integrated, team-based primary care. The waiving or reduction of co-payments and fees that have been observed around the world (including in the Democratic Republic of Congo, Tanzania, Bangladesh, Sri Lanka, and Malaysia) ${ }^{16}$ should be capitalised upon to advance the Universal Health Coverage mandate of comprehensive services without financial hardship. ${ }^{17}$

COVID-19 has shone an uncomfortable spotlight on primary care over the past few months, exposing weaknesses even in the systems commonly held up as paragons of excellence. As primary care is so central to pandemic preparedness, response, and recovery, ${ }^{18}$ as well as attaining healthy and equitable societies ${ }^{19,20}$ it is absolutely imperative that we get it right; financing, resourcing, and structuring services that deliver on the Astana principles that were unanimously endorsed in 2018. Now is the time to rebuild primary care, stronger than ever.

\section{Funding}

There are no funders to declare.

\section{Ethical approval}

N/A

\section{Provenance}

Commissioned not externally reviewed.

\section{Competing interests}

HDM is the Editor in Chief of BJGP Open.

\section{References}

1. OECD. Realising the Potential of Primary Health Care. 2020; https://www.oecd.org/health/realising-the-potentialof-primary-health-care-a92adee4-en.htm (accessed 20 Aug 2020).

2. Starfield B. Is primary care essential? Lancet 1994; 344(8930): 1129-1133. DOI: https://doi.org/10.1016/S01406736(94)90634-3

3. WHO Europe. Primary Health Care; http://www.euro.who.int/en/health-topics/Health-systems/primary-health-care/ main-terminology (accessed 20 Aug 2020).

4. WONCA. Definition of general practice/family medicine; https://www.woncaeurope.org/page/definition-ofgeneral-practice-family-medicine (accessed 20 Aug 2020).

5. WHO. The Declaration of Astana.. 2018; https://www.who.int/docs/default-source/primary-health/declaration/ gcphc-declaration.pdf (accessed 12/08/2020).

6. World Health Organization, United Nations Children's Fund (UNICEF): A vision for primary health care in the 21st century: towards universal health coverage and the Sustainable Development Goals. 2018; https://apps.who.int/ iris/handle/10665/328065 (accessed 20 Aug 2020).

7. Allen LN, Barry E, Gilbert $C$, et al. How to move from managing sick individuals to creating healthy communities. $\mathrm{Br}$ J Gen Pract 2019; 69(678): 8-9. DOI: https://doi.org/10.3399/bjgp19X700337

8. WHO. Primary health care: closing the gap between public health and primary care through integration. 2018; https://www.who.int/docs/default-source/primary-health-care-conference/public-health.pdf?sfvrsn=2ca0881d_2 (accessed 1 Sep 2020).

9. Goodyear-Smith F, Kinder K, Mannie C, et al. Relationship between perceived strength of countries' primary care system and COVID-19 mortality: an international survey study. BJGP Open 2020.DOI: 10.3399/ bjgpopen20X101129.

10. Huston P, Campbell J, Russell G, et al. COVID-19 and primary care in six countries. BJGP Open 2020.DOI: 10.3399/bjgpopen20X101128. 
11. Ngo Bibaa L-AO. Primary health care beyond COVID-19: dealing with the pandemic in Cameroon. BJGP Open 2020.DOI: 10.3399/bjgpopen20X101113.

12. WHO. Operational framework for primary health care Transforming vision into action. 2018; https://www.who.int/ docs/default-source/primary-health-care-conference/operational-framework.pdf?sfvrsn=6e73ae2a_2 (accessed 1 Sep 2020).

13. Allen LN, Barkley S, De Maeseneer J, et al. Unfulfilled potential of primary care in Europe. BMJ 2018; 363(89.k4469. DOI: https://doi.org/10.1136/bmj.k4469

14. Allen LN, Smith RW, Simmons-Jones F. Assessing and addressing the social determinants of noncommunicable diseases in primary care: a systematic review. WHO Bulletin. Article ID: BLT.19.248278; https://www.who.int/ bulletin/online_first/BLT.19.248278.pdf?ua=1 (accessed 2 Sep 2020).

15. The Economist Intelligence Unit. Tracking Covid-19 excess deaths across countries. The Economist [online]. 15 Jul 2020; https://www.economist.com/graphic-detail/2020/07/15/tracking-covid-19-excess-deaths-across-countries (accessed 1 Sep 2020).

16. OECD. Beyond containment: Health system responses to COVID-19 in the OECD. Box 1. Measures implemented to improve affordability to diagnostics and treatment in selected OECD countries. 2020; http://www.oecd.org/ coronavirus/policy-responses/beyond-containment-health-systems-responses-to-covid-19-in-the-oecd-6ab740c0/ (accessed 1 Sep 2020).

17. WHO. Universal Health Coverage; https://www.who.int/healthsystems/universal_health_coverage/en/ (accessed 1 Sep 2020).

18. Dunlop C, Howe A, Li D, Allen LN. The coronavirus outbreak: the central role of primary care in emergency preparedness and response. BJGP Open 2020; 4(1 DOI: https://doi.org/10.3399/bjgpopen20X101041

19. De Maeseneer J. Family Medicine and Primary Care at the Crossroads of Societal Change. Lanoo Campus Publishers: Ghent; 2017.

20. WHO. People-centred and integrated health services: an overview of the evidence: interim report [WHO reference number: WHO/HIS/SDS/2015.7]. World Health Organization; Geneva. 2015; https://www.who.int/servicedeliverys afety/areas/people-centred-care/evidence-overview/en/ (accessed 1 Sep 2020). 